\title{
Development of efficient RNAi methods in the corn leafhopper Dalbulus maidis, a promising application for pest control
}

Dalaisón-Fuentes, L.I. ${ }^{1,2}$; Pascual, A. ${ }^{1,2 *}$; Gazza, E. ${ }^{1,2}$; Welchen, E. ${ }^{4}$, Rivera-Pomar, R. ${ }^{1,2,3}$ and Catalano, M.I. ${ }^{1,2 *}$.

${ }^{1}$ Centro de BioInvestigaciones (Universidad Nacional del Noroeste de la Provincia de Buenos Aires-CICBA), Avenida Presidente Frondizi 2650 (2700), Pergamino, Argentina.

${ }^{2}$ Centro de Investigaciones y Transferencias del Noroeste de la provincia de Buenos Aires (CITNOBA-CONICET), Monteagudo 2772 (2700), Pergamino, Argentina.

${ }^{3}$ Centro Regional de Estudios Genómicos (Facultad de Ciencias Exactas, Universidad Nacional de La Plata), Bvd. 120 y 62 (1900), La Plata, Argentina.

${ }^{4}$ Instituto de Agrobiotecnología del Litoral (CONICET-UNL), Cátedra de Biología Celular y Molecular, Facultad de Bioquímica y Ciencias Biológicas, Universidad Nacional del Litoral, 3000 Santa Fe, Argentina.

*Corresponding authors: apascual@comunidad.unnoba.edu.ar, mariainescatalano@unnoba.edu.ar

\section{ABSTRACT}

BACKGROUND: The corn leafhopper Dalbulus maidis is the main vector of three important stunting pathogens that affect maize production. The most common control strategy against this species is the use of insecticides that provide minimal, short-term protection. In this context, genomic-based technologies such as RNA interference (RNAi) could be a suitable approach to control this pest in a highly specific manner, avoiding the adverse effects associated with insecticide misuse. Therefore, the objective of the present work was to assess the application of RNAi on $D$. maidis through different dsRNA delivery methods and known the function of target gene, Bicaudal C (BicC). 
RESULTS: We have identified and characterized the core components of the RNAi machinery in silico and established two methods of exogenous double-stranded RNAs (dsRNA) delivery to D. maidis. BicC -an important regulator of insect oogenesis- dsRNA was successfully delivered via injection or ingestion to adult females, causing significant reductions in the transcript levels and ovipositions and observable phenotypes in the ovaries when compared to control females. The small doses of $d s R N A^{B i c C}$ administered were enough to trigger a strong RNAi response, demonstrating that D. maidis is highly sensitive to RNAi.

CONCLUSION: This is, to our knowledge, the first report describing RNAi application in $D$. maidis, a tool that can be used to advance towards a novel, insecticide-free control strategy against this pest.

Keywords: Hemiptera, phytophagous, Corn Stunt, pest management, gene silencing.

\section{INTRODUCTION}

The corn leafhopper Dalbulus maidis (DeLong \& Wolcott) (Hemiptera: Auchenorrhyncha) is the main vector of maize rayado fino virus (MRFV) ${ }^{1}$, maize bushy stunt phytoplasma (MBSP) and Spiroplasma kunkelii ${ }^{2}$ that affect maize (Zea mays L.) crops throughout the Americas ${ }^{3}$. D. maidis transmits these pathogens, either alone or in combination, in a persistent-propagative mode ${ }^{4,5}$, causing the diseases referred to as Corn Stunt ${ }^{2,4,5}$. High infestation rates, which can reach $100 \%$ in some areas, may result in yield losses of up to $90 \%$, representing a relevant threat to agriculture ${ }^{6,7}$.

Current control strategies against D. maidis are limited to corn resistant germplasm ${ }^{8}$ and use of insecticides as seed treatments or foliar sprays ${ }^{9-11}$. While insecticides applied to seed treatment only protect the plant at early growth stages, foliar insecticides usually fail to reduce maize damage and incidence of stunting diseases ${ }^{12,13}$, additionally, they cannot discriminate between pest and non-pest species, and widespread use can lead to resistance to them ${ }^{14-16}$. In this context, RNA interference (RNAi) emerges as a promising alternative for vector control ${ }^{17}$.

RNAi is a highly conserved, sequence-specific mechanism ${ }^{18}$ that has been widely used for elucidating gene function, especially in non-model organisms ${ }^{19}$ and in recent years, it has become a powerful tool for insect pest management ${ }^{20-22}$. Briefly, RNAi mechanism consists of two main events: first, exogenously delivered double-stranded RNAs (dsRNA) are internalized 
and processed by the cellular RNAi machinery into small interfering RNA (siRNA), which in second turn triggers the degradation of complementary endogenous messenger RNA (mRNA) leading to gene silencing ${ }^{23-25}$. The core components comprising the RNAi machinery have been identified and characterized in several hemiptera species ${ }^{26-33}$, but the mechanism underlying dsRNA internalization and signal spreading (i.e., systemic RNAi) still remains uncertain ${ }^{34}$.

Most RNAi research has been carried out via microinjection and natural/artificial diets 35-37, and by detached leaf/petiole dip, topical application to either the insect or plant or transgenic plants expressing insect-derived dsRNAs ${ }^{20-22}$, to a lesser extent. Besides the route of entry, RNAi effectiveness has been found to be highly variable among insect species ${ }^{38}$. These variations mainly depend on intrinsic factors of the species, being some orders more refractory to dsRNA administration than others ${ }^{39-41}$, as well as extrinsic factors, including the delivery method and the target gene ${ }^{42}$. However, gene silencing has been successfully achieved in several hemipterans, including the leafhoppers Amrasca biguttula ${ }^{43}$, Circulifer haematoceps ${ }^{44}$, Graminella nigrifrons ${ }^{45}$, Homalodisca vitripennis ${ }^{46,47}$ and Nephotettix cincticeps $^{48-50}$, along with others.

Due to the central role of reproduction on insect life cycle and propagation, we decided to target Bicaudal $C(B i c C)$. It has been demonstrated that $B i c C$ plays a vital role during oogenesis in other hemipterans ${ }^{51,52}$ and in the dipteran Drosophila melanogaster, in which is also responsible for specifying anterior-posterior (AP) polarity of the embryos ${ }^{53-55}$. Here we silenced this gene in order to assess the application of RNAi in D. maidis. We have identified and characterized core components of the RNAi pathway and established two reliable methods of dsRNA delivery. We also describe the essential function of Dmai-BicC in female reproduction, being the first time that this species has been studied from a genetic point of view. Our findings enable further molecular analyses on this leafhopper and provide a framework for developing new control strategies.

\section{MATERIALS AND METHODS}

\subsection{Insect rearing}

A healthy colony of $D$. maidis was maintained on corn plants (Zea mays L.) in our laboratory. The colony was kept in aluminum-framed cages with a fine voile-type nylon mesh 
and placed in a greenhouse at a temperature of $25^{\circ} \mathrm{C}$ and $80 \%$ relative humidity, with a photoperiod of $16: 8$ hours (h) (light: darkness). At $23 \pm 3{ }^{\circ} \mathrm{C}$, embryogenesis is completed 11.5 \pm 1.3 days after egg laying ${ }^{56}$.

\subsection{Evaluation of feeding behavior on artificial diet}

To test whether the insects would feed on the artificial diet containing the dsRNAs, a liquid artificial diet consisting of $10 \%(\mathrm{w} / \mathrm{v})$ sucrose solution ${ }^{57}$ was prepared by dissolving sucrose in sterile water on a magnetic stirrer hotplate $\left(25^{\circ} \mathrm{C}\right)$ and then, green food coloring (Fleibor S.R.L) was added. This mixture was held between two layers of stretched Parafilm M (Bemis ${ }^{\mathrm{TM}}$ ) located at the top end of the feeding chamber. The other end was covered with a fine nylon mesh to allow aeration. Insects were placed inside the feeding chamber during 3-5 h. Chambers were checked during the following days. Electrical penetration graph (EPG) technique was used to corroborate feeding on the artificial $\operatorname{diet}^{58,59}$. The feeding platform was constructed from a small plastic Petri dish according to Trębicki et al. ${ }^{60}$. Insects were monitored for $8 \mathrm{~h}$ in a Giga-8 EPG model (EPG Systems, Wageningen, The Netherlands).

\subsection{Identification of RNAi-related genes and Dmai-BicC}

Gene identification was performed using local $\mathrm{BLAST}^{61}$ on a D. maidis adult transcriptome, previously assembled in our $\operatorname{lab}^{62}$ (File S1). The search of the RNAi machinery genes was limited to Dicer2 (Dcr2), Argonaute2 (Ago2), R2D2 (R2D2) and Systemic RNA interference defective protein 1 (Sid1) proteins from other hemipterans available in the NCBI protein database. Best hits were chosen considering the percent identity (\%ID), match length and E-value $(\leq 1 \mathrm{E}-5)$. ORF finder tool ${ }^{63}$ was used to detect open reading frames (ORFs) in transcript sequences. Protein signatures were predicted by InterProScan (version 5.52-86.0) ${ }^{64}$. Translated sequences were used as a query to perform BLASTp ${ }^{65}$ searches against the nonredundant protein database (version 1.1, accessed September 2021). To provide additional confirmation on identity, each sequence was aligned with orthologues from other species using Clustal $\Omega$ (version 1.2.4) ${ }^{66}$. Conserved transmembrane helices found in Sidl proteins were predicted for Dmai-Sidl at TMHMM Server (version 2.0) ${ }^{67}$. The same workflow was applied for BicC. 


\section{4. dsRNA synthesis}

Total RNA was isolated from ovaries from adult females using TRIzol ${ }^{\mathrm{TM}}$ reagent (Invitrogen), according to manufacturer's instructions. cDNA was synthesized following the EasyScript Reverse Transcriptase (AP-Biotech) protocol and used as a template for RT-PCR. Specific primers for Dmai-BicC were designed ${ }^{68,69}$ to amplify a region of 372 bp (Table S1) within one of the predicted KH domains (Fig. S1). Reaction conditions were 2 minutes (min) at $94^{\circ} \mathrm{C}$, followed by 35 cycles of: $92^{\circ} \mathrm{C}$ for 30 seconds (s), $56^{\circ} \mathrm{C}$ for $30 \mathrm{~s}$ and $72^{\circ} \mathrm{C}$ for $45 \mathrm{~s}$, and a final extension step for $4 \mathrm{~min}$ at $72^{\circ} \mathrm{C}$ (Taq Pegasus, Productos Bio-Lógicos). The integrity of the amplicon was checked in a $1 \%$ agarose gel and sequenced to confirm its identity (Macrogen Inc.).

The dsRNA targeting Dmai-BicC ( $d s R N A^{B i c C}$ ) was synthesized using T7 Polymerase (ThermoFisher), according to the manufacturer's specifications. The same sense and antisense primers were designed containing $\mathrm{T} 7$ promoter sequence at the 5 'end for further use during in vitro transcription (Table S1). dsRNA was purified by DNase digestion (Qiagen). Purified dsRNA was examined in a $1 \%$ agarose gel to ensure its integrity. A negative control was included using the $\beta$-lactamase gene $\left(d s R N A^{\text {Blac }}\right)$ amplified from a pRSET b plasmid ${ }^{70}$. The final doses of dsRNA were $100 \mathrm{ng} / \mu \mathrm{L}\left(d s R N A^{B i c C 100}\right)$ and $200 \mathrm{ng} / \mu \mathrm{L}\left(d s R N A^{B i c 200}\right)$ for $d s R N A^{B i c C}$ and $130-170 \mathrm{ng} / \mu \mathrm{L}$ for $d s R N A^{\text {Blac }}$ treatments.

\section{5. dsRNA feeding}

Newly molted adult females were anesthetized with $\mathrm{CO}_{2}$ and placed inside the feeding chambers where they fed only artificial diet. $24 \mathrm{~h}$ later, the dsRNA was added as a supplement to the diet. Insects fed by puncturing the inner membrane of the diet pouch. This solution was renewed daily for three consecutive days. After three days of dsRNA ingestion, each female was placed individually in a cage and mated with one non-exposed male, allowing them to feed and lay eggs on corn plants. Female mortality and oviposition (i.e., number of eggs laid per female) were recorded every $48 \mathrm{~h}$. Rearing conditions were the same as for the colony.

\section{6. dsRNA microinjection}

Microinjection was performed with a glass needle (P-30 model, Sutter Instrument Company) between two abdominal sternites. Micropipette puller settings were the following: 
950 (heat \#1), 950 (pull) and 3.24-3.25 (optical micrometer). Newly molted adult females were anesthetized with $\mathrm{CO}_{2}$ and placed on a frozen surface, to ensure their lethargy throughout the procedure. After microinjection, the females were placed in individual cages attached to maize plants to allow feeding. $24 \mathrm{~h}$ later, once the females were recovered from injury, one male was introduced into each cage. From this stage on, the experiment continued as described for dsRNA feeding.

\subsection{Ovary and embryo manipulation}

After 18 days since dsRNA administration, ovaries were dissected according to Pascual et al. $^{52}$, but fixation step was limited to $10-15 \mathrm{~min}$.

Ovipositions were monitored during the expected time of embryogenesis ${ }^{56}$ and eggs which did not hatch were fixed as follows: they were collected using insect pins under a stereomicroscope (Zeiss, Stem 305), placed in microtubes and incubated at $-80^{\circ} \mathrm{C}$ for 3-5 min. Then $200 \mu \mathrm{L}$ of PBS $1 \mathrm{X}$ were added and submerged into hot water $\left(85-90^{\circ} \mathrm{C}\right)$ for $1 \mathrm{~min}$. Afterwards, $60 \mu \mathrm{L}$ of $37 \%$ Formaldehyde (FA) were added to the PBS $1 \mathrm{X}$ and fixed for 10-15 min on a shaking platform (150-200 rpm). Subsequently, $260 \mu \mathrm{L}$ of heptane were used to postfix the eggs for 10-15 min on a shaking platform at the same speed. After the two phases separated, the upper phase was removed and the lower phase was rinsed three times with 500 $\mu \mathrm{L}$ of $100 \%$ Methanol $(\mathrm{MeOH})$ followed by high speed vortex. Finally, the chorion and perivitelline membrane of the eggs were manually removed under a stereomicroscope (Zeiss, Stem 305).

For fluorescence microscopy, fixed ovaries and eggs were incubated in a $300 \mathrm{nM}$ DAPI stain solution (4',6-diamidino-2-phenylindole, ThermoFisher Scientific) on a shaking platform (150-200 rpm) for 15-20 min. Prior to staining, eggs were rehydrated through the subsequent series of $\mathrm{MeOH}$ in PBS: 75\% $\mathrm{MeOH} / 25 \% \mathrm{PBS} 1 \mathrm{X}, 50 \% \mathrm{MeOH} / 50 \% \mathrm{PBS} 1 \mathrm{X}$ and 25\% $\mathrm{MeOH} / 75 \%$ PBS 1X, for 3-5 min in each solution. Images were acquired with a stereomicroscope and a fluorescence microscope (Zeiss, Axio Imager A2).

\subsection{Real-time quantitative PCR (RT-qPCR)}

Independent experiments were conducted to determine Dmai-BicC mRNA expression after dsRNA delivery. We decided to evaluate the highest dsRNA concentration $(200 \mathrm{ng} / \mu \mathrm{L})$. Total RNA samples were prepared from ovaries dissected at 1- and 7-days, based on oocyte maturation $^{71,72}$, after completion of dsRNA administration. Ovaries were dissected in PBS 1X 
and immediately stored in TRIzol ${ }^{\mathrm{TM}}$ reagent (Invitrogen) for RNA extraction. RNA was quantified by UV-Vis spectrophotometric measurement in a Nanodrop 2000c Instrument (Thermo Scientific ${ }^{\mathrm{TM}}$ ). Concentration and purity ratios (A260/280 and A260/230) were analyzed. Total RNA of individual replicates was subjected to DNase I, RNase-free (Thermo Scientific ${ }^{\mathrm{TM}}$ ) treatment according to the manufacturer's indications. First strand cDNA synthesis was performed using the $\log 0(\mathrm{dT})_{18}$ primer and RevertAid Reverse Transcriptase (Thermo Scientific ${ }^{\mathrm{TM}}$ ) according to the protocol provided by the manufacturer. Real time (RT)qPCR was carried out in a Bio-Rad ${ }^{\circledR}$ CFX-96 ${ }^{\mathrm{TM}}$ thermocycler in $10 \mu$ final volume reaction using SsoAdvanced ${ }^{\mathrm{TM}}$ Universal SYBR ${ }^{\circledR}$ Green Supermix (Bio-Rad) and $50 \mathrm{pmol}$ of each forward and reverse primer (Table S1). Thermal cycle protocol consisted of $30 \mathrm{~s}$ at $95^{\circ} \mathrm{C}$ for initial denaturation, followed by 35 cycles of $15 \mathrm{~s}$ at $95^{\circ} \mathrm{C}$ for denaturation and $20 \mathrm{~s}$ at $60^{\circ} \mathrm{C}$ for annealing and extension. Melting curve analysis was performed at the end by using instrument default settings $\left(65^{\circ} \mathrm{C}-95^{\circ} \mathrm{C}, 0.5^{\circ} \mathrm{C}\right.$ temperature increment). Relative transcript levels were calculated by a comparative $\mathrm{Ct}$ method ${ }^{73}$. Expression values were normalized using Actin 1 (Dmai-Act1, Table S1), after a screen of several housekeeping-gene candidates, as it provided consistent results on the samples analyzed (data not shown).

\subsection{Statical analysis}

All statistical analyses were performed using the $\operatorname{InfoStat}^{74}$ statistical software. A generalized linear mixed model (GLMM) was applied for the number of eggs laid to model negative binomial variables, being "treatment" the fixed effect and "female" the random effect. The model was adjusted using nlme ${ }^{75}$ and $1 m e 4^{76}$ packages from R language ${ }^{77}$. Predicted values were compared using the DGC test ${ }^{78}$ with a significance level of $5 \%$. Proportions of surviving insects were calculated using the Kaplan-Meier method and the p-values generated via Logrank test were used to test the null hypothesis that the survival curves were identical in the three treatment groups, with a significance level of $5 \%$.

\section{RESULTS}

\subsection{D. maidis feeding on artificial diet}

We confirmed that $D$. maidis adults can survive in vitro for at least five days by feeding exclusively on artificial diet (Fig. 1A-B). Feeding was evidenced by green honeydew droplets 
(Fig. 1C), as a result of the green food coloring included in the diet. Furthermore, insects presented the same green coloration in their mouthparts (Fig. 1D) and abdomen (Fig. 1E), proving that the diet had been ingested and passed through the gut. Furthermore, EPG recordings obtained from $D$. maidis having access to the artificial diet produced the typical waveform correlated with active feeding (Fig. 1F). These results indicate that $D$. maidis feeds reliably on the artificial diet and, therefore, can acquire the dsRNA orally.

\subsection{In silico identification of core RNAi machinery genes on D. maidis}

We identified the active expression of the core components of RNAi machinery on $D$. maidis adult transcriptome (Table 1). Dmai-Dcr2, Dmai-Ago2, Dmai-R2D2 and Dmai-Sid1 translated sequences all showed the protein signatures characteristic of the corresponding families previously described (Fig. S2). Sequence similarity searches against the protein database revealed high similarity with orthologs from closely related insect species, providing further confirmation of their identity (data not shown). Altogether, these results demonstrate that the genes involved in RNAi (siRNA) pathway are conserved in D. maidis.

\subsection{Effect of RNAi on female survival and fertility}

To determine the efficiency of RNAi gene silencing on D. maidis, female mortality and oviposition were recorded at 2-day intervals. No significant differences were found in the proportion of living females throughout the experiments (Fig. S3), regardless of the delivery method employed (microinjection: $\mathrm{p}=0.9475$ and feeding: $\mathrm{p}=0.1406$ ).

For the microinjection assay, both doses of $d s R N A^{B i c C}(100$ and $200 \mathrm{ng} / \mu \mathrm{L}$, $d s R N A^{B i c C 100}$ and $d s R N A^{B i c C 200}$, respectively) reduced significantly the ovipositions when compared to the $d s R N A^{\beta l a c}$ females, remaining close to zero throughout the experiment. Also, significant differences between both $d s \mathrm{RNA}^{B i c C}$ concentrations were observed (Fig. 2A). Similarly, both $d s R N A^{B i c C 100}$ and $d s R N A^{B i c C 200}$-fed females had significantly lower ovipositions

than those in the control ones; however, they laid more eggs than the $d s R N A^{B i c C}$-injected females. No significant differences between the $d s R N A^{B i c C}$ concentrations were detected for the feeding assay (Fig. 2B).

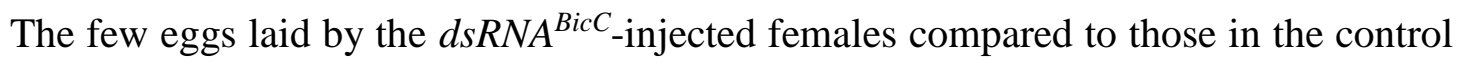
(Fig. 2A and S4A) were smaller, thinner and had abnormally large bubbles in the yolk (Fig. S4B). None of them hatched and had no distinguishable embryonic structures, indicating that 
embryogenesis was affected (Fig. 2B). Unlike $d s R N A^{B i c C}$-injected females, most of the eggs laid by $d s R N A^{B i c C}$-fed females reached first-instar larvae within the expected time (Fig. 2C and S4C). These results indicate that microinjection and ingestion of dsRNA can successfully trigger an RNAi response in D. maidis.

\subsection{Effect of RNAi on Dmai-Bic transcript levels}

Delivery of $d s R N A^{B i c C}$ by microinjection resulted in significant reductions in DmaiBicC transcripts when compared to the $d s R N A^{\text {Blac }}$ control group $(\mathrm{p} \leq 0,005)$. The strongest silencing of Dmai-BicC was measured at day 7 after dsRNA administration, with a decreasing of a fold change near to 3.2 times at 1 day after treatment and more than 170 times at day 7 in $d s R N A^{B i c C}$-injected females in comparison to the expression in control ones (Fig. 3A). Significant differences in the abundance of Dmai-BicC transcripts were also detected between the females fed with $d s R N A^{B i c C}$ and those with $d s R N A^{\text {Blac }}(\mathrm{p} \leq 0,005)$ at 1 day and 7 days after dsRNA delivery, decreasing 2.6 and 3.7 times respectively (Fig. 3B). A greater and faster reduction in Dmai-BicC transcript abundance was obtained by microinjection rather than feeding.

\subsection{Dmai-BicC role during oogenesis}

Morphological examination of the ovaries under stereomicroscope showed that $87,5 \%$ of the females injected with $d s R N A^{B i c C 100}$ presented the phenotype in Fig. 4B. The rest of them exhibited the same characteristics as $d s R N A^{\beta l a c}$-injected females (Fig. 4A). This percentage increased to $100 \%$ for the group injected with $d s R N A^{B i c C 200}$. Silenced females had the same number of tubular-shaped ovarioles - germarium and developing oocytes surrounded by follicle cells- as the controls, but retained a greater number of oocytes, as they failed to advance towards choriogenesis. In addition to their smaller size, the cytoplasm of the oocytes displayed a white coloration, in opposition to the translucent cytoplasm of control vitellogenic oocytes. Conversely, alterations in the ovaries of $d s R N A^{B i c}$-fed females ranged from control (average of 79,7\%) (Fig. 4C and S5A) to a variety of morphological defects (13.3\% and $27.3 \%$ of the females fed with $d s R N A^{B i c C 100}$ and $d s R N A^{B i c C 200}$, respectively) (Fig. S5B-C).

The ovaries dissected from injected females were analyzed in more detail by DIC optics and nuclei staining to determine cell distribution. We corroborated that $d s R N A^{B i c C} \operatorname{did}$ not produce changes in the germarium (data not shown). The follicular epithelium was present in 
the ovaries of silenced females, but as the oocytes advanced through the ovariole they got progressively more folded and wrinkled (Fig. 5D), causing the follicular cells to lose the regular columnar shape seen in control females (Fig. 5A). Likewise, nuclei became closer to each other to the point of overlapping, with no intercellular space left among them (Fig. 5E-F).

These phenotypes agree with the observed reduction in the transcript levels and ovipositions and support the idea that the lack of Dmai-BicC affects oogenesis and oocyte maturation.

\section{DISCUSSION}

Developing new, RNAi-based control strategies is crucial in order to achieve specific pest control ${ }^{79}$. Finding suitable dsRNA delivery methods constitute the first step for the development of these control techniques ${ }^{35,80}$. This study presents, to the best of our knowledge, the first procedure for dsRNA delivery in D. maidis via microinjection and feeding and successfully silenced Dmai-BicC, an essential gene of oogenesis, thus providing with a potential tool to control this pest in a specific, sustainable way.

Core RNAi machinery genes -Dcr2, Ago2 and R2D2- were found in D. maidis adult transcriptome, as have been reported in several hemipterans ${ }^{26,27,29,30,32,33}$, with the exception of Halyomorpha halys ${ }^{28}$ and Diaphorina citri $^{31}$, in which $R 2 D 2$ was shown to be absent. We were also able to identify Sid1, a key component in the uptake and systemic spread of dsRNA ${ }^{81}$. Sidlike channel proteins have been characterized in many phytophagous species ${ }^{26,27,29-31}$, excluding some bug species ${ }^{28,33}$. The presence of these core genes in our transcriptomic database clearly indicates that the RNAi pathway is conserved in D. maidis.

In this context, we established an in vitro rearing system that allowed us to easily deliver the dsRNA. The addition of green food coloring served as proof of diet ingestion, using the same approach as Ghosh et al. ${ }^{80}$ for evaluating the potential of green beans to deliver dsRNA in the brown marmorated stink bug, H. halys. Parallel EPG recordings confirmed our observations and were consistent with previous studies in other leafhoppers, such as Empoasca vitis $^{82}$ and Orosius orientalis ${ }^{60}$, where active feeding in artificial diets was demonstrated.

To assess the application of RNAi on D. maidis, we first attempted to silence a gene in adult insects that led to a visible non-lethal phenotype, but provides the opportunity to control this species by reducing the rate of population increase. Both methods -microinjection and feeding- significantly lowered transcript abundance and egg production, but differed in the morphological alterations generated in the ovaries. Our findings also revealed that D. maidis is 
sensitive to RNAi, as small doses of dsRNA (100-200 ng/ $\mu \mathrm{L})$ could induce strong RNAi responses, analogous to that reported by Taning et al. ${ }^{31}$ in the Asian citrus psyllid, D. citri.

The efficiency of oral delivery in knocking down the target gene was not as high as that accomplished by microinjection, in agreement with earlier research in the corn planthopper Peregrinus maidis ${ }^{72}$. These differences between delivery methods may be attributed to the lower amount of dsRNA delivered to D. maidis females by ingestion and/or the rapid degradation of dsRNA in the diet prior to ingestion, or in the digestive tract of the insects after feeding. In accordance with this, the presence of adverse $\mathrm{pH}$ conditions and dsRNA-degrading nucleases in the saliva, hemolymph and gut has been associated to weak (or null) gene silencing response in other hemipterans, as Acyrthosiphon pisum $^{83}$, Lygus lineolaris $^{84}$ and Myzus persicae $^{85}$.

Regarding Dmai-BicC, we were unable to identify any structures in the few eggs laid by $d s R N A^{B i c C}$-injected females, except for the presence of endosymbiont organisms, previously described in D. maidis ${ }^{86-88}$. Similar outcomes were achieved in the blood-sucking bug Rhodnius prolixus, suggesting that $\mathrm{BicC}$ role during hemipteran embryogenesis, could be prior to gastrulation ${ }^{52}$. Although most of the $d s R N A^{B i c C}$-fed females did lay eggs, we assign this phenomenon to the less amount of dsRNA consumed by these females, rather than a real difference in Dmai-BicC function. Unlike D. melanogaster, embryos presented no AP patterning defects ${ }^{53,54}$ and displayed the same phenotype as the control ones. $d s R N A^{B i c C}$ microinjection into D. maidis females also resulted in a high percentage of sterility, agreeing with the disruption of BicC orthologs in $N$. lugens ${ }^{51}$ and D. melanogaster ${ }^{55}$ females. $^{2}$

Remarkably, the ovaries of $d s R N A^{B i c C}$-injected females shared some characteristics of atresia described in the bugs $R$. prolixus ${ }^{89-91}$ and Dipetalogaster maxima ${ }^{92}$, such as color changes in the cytoplasm of the oocytes and loss of columnar shape in some follicular cells. Follicular atresia is the mechanism by which the oocyte contents are degraded in response to stress conditions, allowing the energetic resources of the developing oocytes to be reallocated ${ }^{93}$. As this process has the ultimate goal of restoring female fitness and the most damaged ovaries corresponded to $d s R N A^{B i c C}$-fed females, it could be possible that the absence of some essential nutrients in the artificial diet may have contributed to an atretic-like phenotype, worsening the effects of Dmai-BicC silencing. In this sense, previous studies found that fertility was compromised in artificially-reared insects compared to those fed on plants ${ }^{94,95}$.

In summary, development of RNAi delivery methods, added to the availability of omics data will provide insights into the signaling networks controlling insect life cycle and 
propagation. In this regard, it is certain that Dmai-BicC is a key player in the reproduction of D. maidis.

\section{CONCLUSION}

This study provides evidence of a functional RNAi machinery in D. maidis and constitutes, to the best of our knowledge, the first report of RNAi in adult insects of this species. On the basis of our results, we propose that oogenesis-related genes, such as Dmai-BicC, are promising targets by inducing reproductive arrest of the females, hence preventing pest propagation. Considering both delivery methods, we believe that microinjection represents a robust technique for elucidating gene function, while oral administration could be the way forward in developing effective and sustainable RNAi-based control strategies against this leafhopper.

\section{ACKNOWLEDGEMENTS}

The authors thank the Centro de Investigaciones Básicas y Aplicadas (CIBA) for kindly allowing the use of their microscope facility.

\section{CONFLICT OF INTEREST STATEMENT}

The authors declare no conflict of interest.

\section{REFERENCES}

1. Gamez R. Transmission of rayado fino virus of maize (Zea mays) by Dalbulus maidis. Annals of Applied Biology 73(3): 285-292 (1973).

2. Nault LR. Maize bushy stunt and corn stunt: a comparison of disease symptoms, pathogen host ranges, and vectors. Phytopathology 70(7): 659-62 (1980).

3. Triplehorn BW, Nault LR. Phylogenetic Classification of the Genus Dalbulus (Homoptera: Cicadellidae), and Notes on the Phylogeny of the Macrostelini. Annals of the Entomological Society of America 78(3): 291-315 (1985).

4. Nault L, Bradfute O. Corn stunt: involvement of a complex of leafhopper-borne pathogens, in Leafhopper Vectors and Plant Disease Agents ed. by Maramorosch K., Harris K. F. New York: Academic Press pp. 561-85 (1979).

5. Hruska AJ, Peralta MG. Maize response to corn leafhopper (Homoptera: Cicadellidae) infestation and achaparramiento disease. Journal of Economic Entomology 90(2): 604-10 (1997). 
6. Giménez Pecci M de la P, Laguna IG, Avila AO, Marino de Remes Lenicov AM, Virla EG, Borgogno C, et al. Difusión del Corn Stunt Spiroplasma del maíz (Spiroplasma kunkelii) y del vector (Dalbulus maidis) en la República Argentina. Revista de la Facultad de Agronomía 105 (2002).

7. $\quad$ Oliveira E de, Resende R de O, Giménez Pecci M de la P, Laguna IG, Herrera P, Cruz I. Incidência de viroses e enfezamentos e estimativa de perdas causadas por molicutes em milho no Paraná. Pesquisa Agropecuária Brasileira 38: 19-25 (2003).

8. Oleszczuk JD, Catalano MI, Dalaisón L, di Rienzo JA, Giménez Pecci M de la P, Carpane P. Characterization of components of resistance to Corn Stunt disease. Plos one 15(10): e0234454 (2020).

9. Bhirud KM, Pitre HN. Bioactivity of systemic insecticides in corn: Relationship to leafhopper vector control and corn stunt disease incidence. Journal of economic entomology 65(4): 113440 (1972).

10. Perfecto I. Indirect and direct effects in a tropical agroecosystem: the maize-pest-ant system in Nicaragua. Ecology 71(6): 2125-34 (1990).

11. Tsai JH, Steinberg B, Falk BW. Effectiveness and residual effects of seven insecticides on Dalbulus maidis (Homoptera: Cicadellidae) and Peregrinus maidis (Homoptera: Delphacidae). Journal of Entomological Science 25(1): 106-11 (1990).

12. Oliveira CM, Oliveira E de, Canuto M, Cruz I. Controle químico da cigarrinha-do-milho e incidência dos enfezamentos causados por molicutes. Pesquisa agropecuária brasileira 42: 297303 (2007).

13. Oliveira CM, Lopes JRS, Nault LR. Survival strategies of Dalbulus maidis during maize offseason in Brazil. Entomologia Experimentalis et Applicata 147(2): 141-53 (2013).

14. Georghiou GP, Lagunes-Tejeda A. The occurrence of resistance to pesticides in arthropods (1991).

15. Naqqash MN, Gökçe A, Bakhsh A, Salim M. Insecticide resistance and its molecular basis in urban insect pests. Parasitology research 115(4): 1363-73 (2016).

16. le Goff G, Giraudo M. Effects of pesticides on the environment and insecticide resistance in Olfactory Concepts of Insect Control-Alternative to Insecticides. Springer pp. 51-78 (2019).

17. Fletcher SJ, Reeves PT, Hoang BT, Mitter N. A perspective on RNAi-based biopesticides. Frontiers in plant science 11:51 (2020).

18. Fire A, Xu S, Montgomery MK, Kostas SA, Driver SE, Mello CC. Potent and specific genetic interference by double-stranded RNA in Caenorhabditis elegans. Nature 391(6669): 806-11 (1998).

19. Bellés X. Beyond Drosophila: RNAi in vivo and functional genomics in insects. Annual review of entomology 55: 111-28 (2010).

20. Baum JA, Bogaert T, Clinton W, Heck GR, Feldmann P, Ilagan O, et al. Control of coleopteran insect pests through RNA interference. Nature Biotechnology 25(11): 1322-6 (2007).

21. Mao Y-B, Cai W-J, Wang J-W, Hong G-J, Tao X-Y, Wang L-J, et al. Silencing a cotton bollworm P450 monooxygenase gene by plant-mediated RNAi impairs larval tolerance of gossypol. Nature Biotechnology 25(11): 1307-13 (2007).

22. Head GP, Carroll MW, Evans SP, Rule DM, Willse AR, Clark TL, et al. Evaluation of SmartStax and SmartStax PRO maize against western corn rootworm and northern corn rootworm: efficacy and resistance management. Pest management science 73(9): 1883-99 (2017).

23. Elbashir SM, Lendeckel W, Tuschl T. RNA interference is mediated by 21-and 22-nucleotide RNAs. Genes \& development 15(2): 188-200 (2001).

24. Tomari Y, Zamore PD. Perspective: machines for RNAi. Genes \& Development 19(5): 517-29 (2005). 
25. Zotti M, dos Santos EA, Cagliari D, Christiaens O, Taning CNT, Smagghe G. RNA interference technology in crop protection against arthropod pests, pathogens and nematodes. Pest Management Science 74(6): 1239-50 (2018).

26. Bansal R, Michel AP. Core RNAi machinery and Sid1, a component for systemic RNAi, in the hemipteran insect, Aphis glycines. International Journal of Molecular Sciences 14(2): 3786-801 (2013).

27. Xu H-J, Chen T, Ma X-F, Xue J, Pan P-L, Zhang X-C, et al. Genome-wide screening for components of small interfering RNA (siRNA) and micro-RNA (miRNA) pathways in the brown planthopper, Nilaparvata lugens (Hemiptera: Delphacidae). Insect Molecular Biology 22(6): 635-47 (2013).

28. Sparks ME, Shelby KS, Kuhar D, Gundersen-Rindal DE. Transcriptome of the Invasive Brown Marmorated Stink Bug, Halyomorpha halys (Stål) (Heteroptera: Pentatomidae). Plos one 9(11): e111646 (2014).

29. Upadhyay SK, Dixit S, Sharma S, Singh H, Kumar J, Verma PC, et al. siRNA Machinery in Whitefly (Bemisia tabaci). Plos one 8(12): e83692 (2014).

30. Nicholson SJ, Nickerson ML, Dean M, Song Y, Hoyt PR, Rhee H, et al. The genome of Diuraphis noxia, a global aphid pest of small grains. BMC Genomics 16(1): 429 (2015).

31. Taning CNT, Andrade EC, Hunter WB, Christiaens O, Smagghe G. Asian Citrus Psyllid RNAi Pathway-RNAi evidence. Scientific Reports 6(1): 1-10 (2016).

32. Davis-Vogel C, van Allen B, van Hemert JL, Sethi A, Nelson ME, Sashital DG. Identification and comparison of key RNA interference machinery from western corn rootworm, fall armyworm, and southern green stink bug. Plos one 13(9): e0203160 (2018).

33. Cagliari D, Días NP, dos Santos EÁ, Rickes LN, Kremer FS, Farias JR, et al. First transcriptome of the Neotropical pest Euschistus heros (Hemiptera: Pentatomidae) with dissection of its siRNA machinery. Scientific Reports 10(1): 1-16 (2020).

34. Jain RG, Robinson KE, Asgari S, Mitter N. Current scenario of RNAi-based hemipteran control. Pest Management Science 77(5): 2188-2196 (2021).

35. Huvenne H, Smagghe G. Mechanisms of dsRNA uptake in insects and potential of RNAi for pest control: a review. Journal of insect physiology 56(3): 227-35 (2010).

36. Yu N, Christiaens O, Liu J, Niu J, Cappelle K, Caccia S, et al. Delivery of dsRNA for RNAi in insects: an overview and future directions. Insect Science 20(1): 4-14 (2013).

37. Cagliari D, Dias NP, Galdeano DM, dos Santos EÁ, Smagghe G, Zotti MJ. Management of pest insects and plant diseases by non-transformative RNAi. Frontiers in plant science 10: 1319 (2019).

38. Cooper AMW, Silver K, Zhang J, Park Y, Zhu KY. Molecular mechanisms influencing efficiency of RNA interference in insects. Pest management science 75(1): 18-28 (2019).

39. Tomoyasu Y, Miller SC, Tomita S, Schoppmeier M, Grossmann D, Bucher G. Exploring systemic RNA interference in insects: a genome-wide survey for RNAi genes in Tribolium. Genome Biology 9(1): R10 (2008).

40. Wang K, Peng Y, Pu J, Fu W, Wang J, Han Z. Variation in RNAi efficacy among insect species is attributable to dsRNA degradation in vivo. Insect biochemistry and molecular biology 77: 19 (2016).

41. Singh IK, Singh S, Mogilicherla K, Shukla JN, Palli SR. Comparative analysis of doublestranded RNA degradation and processing in insects. Scientific Reports 7(1): 1-12 (2017).

42. Baum JA, Roberts JK. Progress Towards RNAi-Mediated Insect Pest Management in Advances in Insect Physiology. Academic Press Inc pp. 249-95 (2014). 
43. Singh S, Gupta M, Pandher S, Kaur G, Rathore P, Palli SR. Selection of housekeeping genes and demonstration of RNAi in cotton leafhopper, Amrasca biguttula biguttula (Ishida). Plos one 13(1): e0191116 (2018).

44. Eliautout R, Dubrana M-P, Vincent-Monégat C, Vallier A, Braquart-Varnier C, Poirié M, et al. Immune response and survival of Circulifer haematoceps to Spiroplasma citri infection requires expression of the gene hexamerin. Developmental \& Comparative Immunology 54(1): 7-19 (2016).

45. Chen Y, Redinbaugh MG, Michel AP. Molecular interactions and immune responses between Maize fine streak virus and the leafhopper vector Graminella nigrifrons through differential expression and RNA interference. Insect Molecular Biology 24(3): 391-401 (2015).

46. Rosa C, Kamita SG, Dequine H, Wuriyanghan H, Lindbo JA, Falk BW. RNAi effects on actin mRNAs in Homalodisca vitripennis cells. Journal of RNAi and gene silencing 6(1): 361-6 (2010). Available from: https://pubmed.ncbi.nlm.nih.gov/20628496

47. Rosa C, Kamita SG, Falk BW. RNA interference is induced in the glassy winged sharpshooter Homalodisca vitripennis by actin dsRNA. Pest Management Science 68(7): 995-1002 (2012).

48. Tomizawa M, Noda H. High mortality caused by high dose of dsRNA in the green rice leafhopper Nephotettix cincticeps (Hemiptera: Cicadellidae). Applied entomology and zoology 48(4): 553-9 (2013).

49. Matsumoto Y, Hattori M. Gene silencing by parental RNA interference in the green rice leafhopper, Nephotettix cincticeps (Hemiptera: Cicadellidae). Archives of insect biochemistry and physiology 91(3): 152-64 (2016).

50. Matsumoto Y, Hattori M. The green rice leafhopper, Nephotettix cincticeps (Hemiptera: Cicadellidae), salivary protein NcSP75 is a key effector for successful phloem ingestion. Plos one 13(9): e0202492 (2018).

51. Zhang BX, Huang HJ, Yu B, Lou YH, Fan HW, Zhang CX. Bicaudal-C plays a vital role in oogenesis in Nilaparvata lugens (Hemiptera: Delphacidae). Journal of Insect Physiology 79: 19-26 (2015).

52. Pascual A, Vilardo ES, Taibo C, Sabio y García J, Pomar RR. Bicaudal C is required for the function of the follicular epithelium during oogenesis in Rhodnius prolixus. Development Genes and Evolution 231(1): 33-45 (2021).

53. Nüsslein-Volhard C. Genetic analysis of pattern-formation in the embryo of Drosophila melanogaster. Wilhelm Roux's archives of developmental biology 183(3): 249-68 (1977).

54. Mohler J, Wieschaus EF. Dominant maternal-effect mutations of Drosophila melanogaster causing the production of double-abdomen embryos. Genetics 112(4): 803-22 (1986).

55. Schüpbach T, Wieschaus E. Female sterile mutations on the second chromosome of Drosophila melanogaster. II. Mutations blocking oogenesis or altering egg morphology. Genetics 129(4): 1119-36 (1991).

56. Remes Lenicov A, Virla E. Aportes al conocimiento de la biología de Dalbulus maidis (Homoptera-Cicadellidae) en condiciones de laboratorio. Neotrópica 39(101-102): 103-9 (1993).

57. Alivizatos SA. Feeding behavior of the spiroplasma vectors Dalbulus maidis and Euscelidius variegatus in vivo and in vitro. Chronika Benaki Phytopathological Institutu (Greece) (1982).

58. McLean DL, Kinsey MG. A Technique for Electronically Recording Aphid Feeding and Salivation. Nature 202(4939): 1358-9 (1964).

59. Tjallingii W. Electronic recording of penetration behaviour by aphids. Entomologia Experimentalis et Applicata 24(3): 721-30 (1978). 
60. Trębicki P, Tjallingii WF, Harding RM, Rodoni BC, Powell KS. EPG monitoring of the probing behaviour of the common brown leafhopper Orosius orientalis on artificial diet and selected host plants. Arthropod-Plant Interactions 6(3): 405-15 (2012).

61. Altschul SF, Gish W, Miller W, Myers EW, Lipman DJ. Basic local alignment search tool. Journal of Molecular Biology 215(3): 403-10 (1990).

62. Palacio V. Secuenciación del Transcriptoma de Dalbulus maidis. Tesis de Maestría, Universidad Nacional del Noroeste de la Provincia de Buenos Aires (2018).

63. Bethesda (MD): National Library of Medicine (US) NC for BI. Open Reading Frame Finder (2004) [cited 2021 Oct 24]. Available from: https://www.ncbi.nlm.nih.gov/orffinder

64. Zdobnov EM, Apweiler R. InterProScan - an integration platform for the signature-recognition methods in InterPro. Bioinformatics 17(9): 847-8 (2001).

65. Johnson M, Zaretskaya I, Raytselis Y, Merezhuk Y, McGinnis S, Madden TL. NCBI BLAST: a better web interface. Nucleic Acids Research 36(suppl_2): W5-9 (2008).

66. Sievers F, Wilm A, Dineen D, Gibson TJ, Karplus K, Li W, et al. Fast, scalable generation of high-quality protein multiple sequence alignments using Clustal Omega. Molecular Systems Biology 7(1): 539 (2011).

67. Krogh A, Larsson B, von Heijne G, Sonnhammer ELL. Predicting transmembrane protein topology with a hidden markov model: application to complete genomes. Journal of Molecular Biology 305(3): 567-80 (2001).

68. Rozen S, Skaletsky H. Primer3 on the WWW for General Users and for Biologist Programmers in Bioinformatics Methods and Protocols ed by Misener S, Krawetz SA Humana Press, Totowa, NJ pp. 365-386 (2000).

69. Stothard P. The Sequence Manipulation Suite: JavaScript Programs for Analyzing and Formatting Protein and DNA Sequences. BioTechniques 28(6): 1102-4 (2000).

70. Lavore A, Pagola L, Esponda-Behrens N, Rivera-Pomar R. The gap gene giant of Rhodnius prolixus is maternally expressed and required for proper head and abdomen formation. Developmental biology 361(1): 147-55 (2012).

71. Li J, Chen Q, Lin Y, Jiang T, Wu G, Hua H. RNA interference in Nilaparvata lugens (Homoptera: Delphacidae) based on dsRNA ingestion. Pest Management Science 67(7): 852-9 (2011).

72. Yao J, Rotenberg D, Afsharifar A, Barandoc-Alviar K, Whitfield AE. Development of RNAi Methods for Peregrinus maidis, the Corn Planthopper. Plos one 8(8): e70243 (2013).

73. Rao X, Huang X, Zhou Z, Lin X. An improvement of the $2^{\wedge}$ (-delta delta CT) method for quantitative real-time polymerase chain reaction data analysis. Biostatistics, bioinformatics and biomathematics 3(3):71 (2013).

74. di Rienzo J.A., Casanoves F., Balzarini M.G., Gonzalez L., Tablada M., Robledo C.W. InfoStat versión 2020. Centro de Transferencia InfoStat, FCA, Universidad Nacional de Córdoba, Argentina. URL http://www.infostat.com.ar.

75. Pinheiro J, Bates D, DebRoy S, Sarkar D, Team RC. Linear and nonlinear mixed effects models. R package version 3(57):1-89 (2007).

76. Bates D, Sarkar D, Bates MD, Matrix L. The lme4 package. R package version 2(1):74 (2007).

77. R Core Team. R: A language and environment for statistical computing (2013).

78. di Rienzo JA, Guzmán AW, Casanoves F. A multiple-comparisons method based on the distribution of the root node distance of a binary tree. Journal of agricultural, biological, and environmental statistics. 2002;7(2):129-42.

79. Vogel E, Santos D, Mingels L, Verdonckt TW, Broeck J vanden. RNA interference in insects: Protecting beneficials and controlling pests. Frontiers in physiology 9: 1912 (2019). 
80. Ghosh SKB, Hunter WB, Park AL, Gundersen-Rindal DE. Double-stranded RNA oral delivery methods to induce RNA interference in phloem and plant-sap-feeding hemipteran insects. Journal of Visualized Experiments (135): e57390 (2018).

81. Winston W M, Molodowitch C, Hunter C P. Systemic RNAi in C. elegans Requires the Putative Transmembrane Protein SID-1. Science 295(5564): 2456-9 (2002).

82. Jin S, Chen ZM, Backus EA, Sun XL, Xiao B. Characterization of EPG waveforms for the tea green leafhopper, Empoasca vitis Göthe (Hemiptera: Cicadellidae), on tea plants and their correlation with stylet activities. Journal of insect physiology 58(9): 1235-44 (2012).

83. Christiaens O, Swevers L, Smagghe G. DsRNA degradation in the pea aphid (Acyrthosiphon pisum) associated with lack of response in RNAi feeding and injection assay. Peptides 53: 30714 (2014).

84. Allen ML, Walker WB. Saliva of Lygus lineolaris digests double stranded ribonucleic acids. Journal of Insect Physiology 58(3): 391-6 (2012).

85. Ghodke AB, Good RT, Golz JF, Russell DA, Edwards O, Robin C. Extracellular endonucleases in the midgut of Myzus persicae may limit the efficacy of orally delivered RNAi. Scientific reports 9(1): 1-14 (2019).

86. Chang HH, Cho ST, Canale MC, Mugford ST, Lopes JRS, Hogenhout SA, et al. Complete genome sequence of "Candidatus Sulcia muelleri" ML, an obligate nutritional symbiont of maize leafhopper (Dalbulus maidis). Genome Announcements 3(1): e01483-14 (2015).

87. Brentassi ME, Franco E, Balatti P, Medina R, Bernabei F, Marino de Remes Lenicov AM. Bacteriomes of the corn leafhopper, Dalbulus maidis (DeLong \& Wolcott, 1923) (Insecta, Hemiptera, Cicadellidae: Deltocephalinae) harbor Sulcia symbiont: molecular characterization, ultrastructure, and transovarial transmission. Protoplasma. 254(3): 1421-9 (2017).

88. Dalaisón-Fuentes LI. Embriología de Dalbulus maidis. Tesis de Grado, Universidad Nacional del Noroeste de la Provincia de Buenos Aires (2018).

89. Huebner E. Oocyte-Follicle Cell Interaction during Normal Oogenesis and Atresia in an Insect. Journal of ultrastructure research 74(1): 95-104 (1981).

90. Medeiros MN, Ramos IB, Oliveira DMP, da Silva RCB, Gomes FM, Medeiros LN, et al. Microscopic and molecular characterization of ovarian follicle atresia in Rhodnius prolixus Stahl under immune challenge. Journal of Insect Physiology 57(7): 945-53 (2011).

91. Pereira J, Diogo C, Fonseca A, Bomfim L, Cardoso P, Santos A, et al. Silencing of RpATG8 impairs the biogenesis of maternal autophagosomes in vitellogenic oocytes, but does not interrupt follicular atresia in the insect vector Rhodnius prolixus. Plos Neglected Tropical Diseases 14(1): e0008012 (2020).

92. Aguirre SA, Pons P, Settembrini BP, Arroyo D, Canavoso LE. Cell death mechanisms during follicular atresia in Dipetalogaster maxima, a vector of Chagas' disease (Hemiptera: Reduviidae). Journal of Insect Physiology 59(5): 532-41 (2013).

93. Bell W, Bohm M. Oosorption in insects. Biological Reviews 50(4): 373-96 (1975).

94. Mitsuhashi J. Artificial rearing and aseptic rearing of leafhopper vectors: Applications in virus and MLO research in Leafhopper Vectors and Plant Disease Agents. Academic Press pp. 369412 (1979).

95. Adams TS. Effect of Diet and Mating Status on Ovarian Development in a Predaceous Stink Bug Perillus bioculatus (Hemiptera: Pentatomidae). Annals of the Entomological Society of America 93(3):529-35 (2000). 
Table 1. Identification of the genes involved in the activation of the silencing machinery and dsRNA uptake in $D$. maidis.

\begin{tabular}{|c|c|c|c|c|c|c|c|c|}
\hline \multirow{2}{*}{ Annotation } & \multirow{2}{*}{ Transcript ID } & \multirow{2}{*}{ cDNA(bp) } & \multirow{2}{*}{ ORF } & \multirow{2}{*}{ EPL (aa) } & \multicolumn{4}{|c|}{ BLASTx } \\
\hline & & & & & Best hit & $\%$ ID & Match length & E-value \\
\hline Dcr-2 & TRINITY_DN24319_c0_g1_i1 & 5.719 & $81-5.084$ & 1.667 & $N c(\mathrm{APF} 46959.1)$ & 63,19 & 1.668 & 0.0 \\
\hline Ago-2 & TRINITY_DN25305_c1_g2_i2 & 5.267 & $5.168-2.451$ & 905 & $R d(\mathrm{AMN} 92166.1)$ & 99,77 & 854 & 0.0 \\
\hline$R 2 D 2$ & TRINITY_DN22775_c0_g2_i1 & 2.052 & $1.738-518$ & 406 & $N v(\mathrm{AVK} 59464.1)$ & 37,77 & 188 & $1.97 \mathrm{e}-29$ \\
\hline Sid-1 & TRINITY_DN25274_c0_g1_i2 & 4.365 & $3.954-1.603$ & 783 & $N l(\mathrm{AGH} 30336.1)$ & 44,51 & 737 & 0.0 \\
\hline
\end{tabular}

Annotations were assessed by sequence similarity search. cDNA: transcript length; ORF: Open Reading Frame; EPL: Encoded Protein Length; Best hit: the closest match found by local BLASTx searches; \% ID (percent identity), match length and e-value to the best hit. Nc: Nephotettix cincticeps, Rd: Recilia dorsalis, Nv: Nezara viridula and Nl: Nilaparvata lugens. 
Figure 1
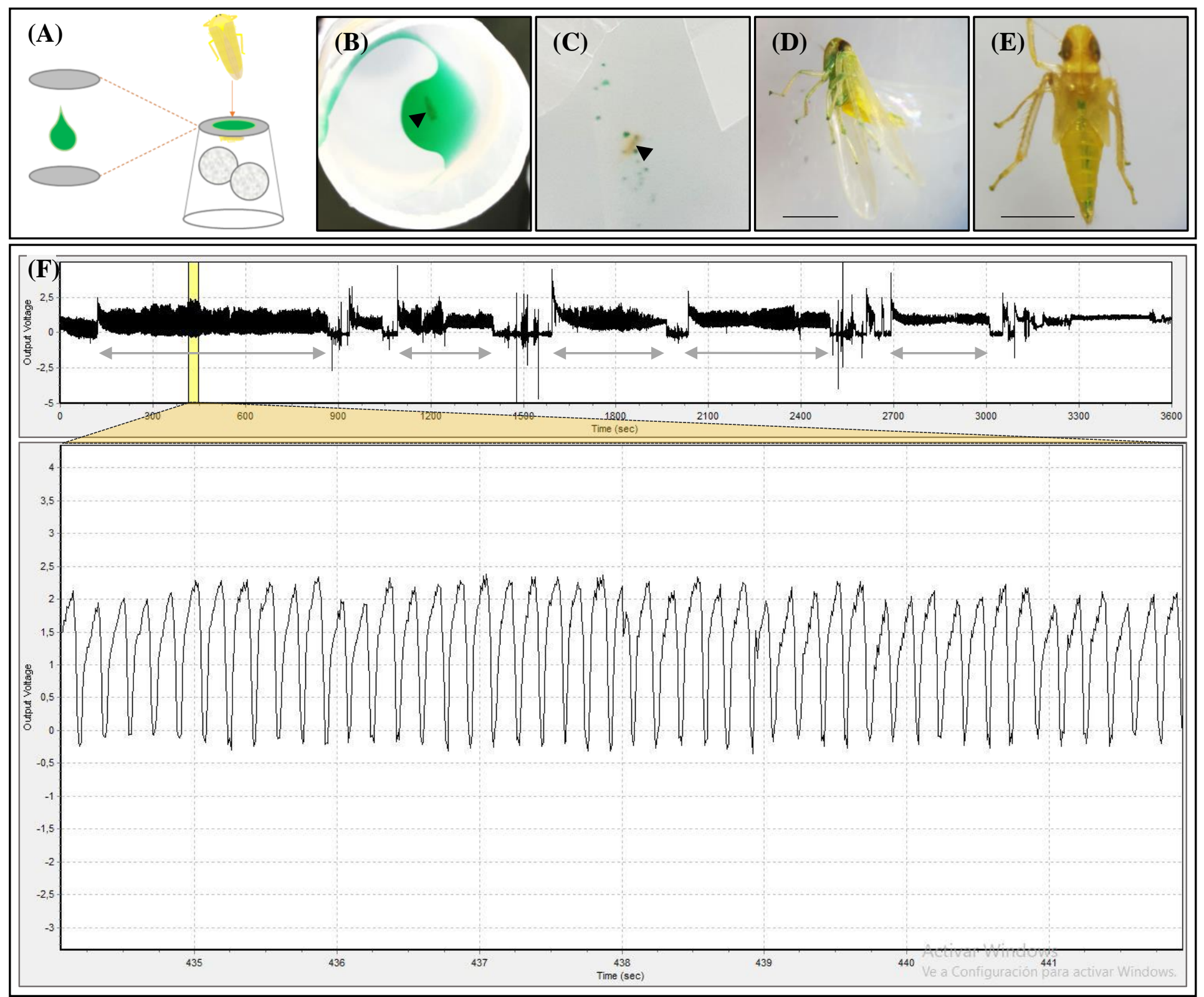

Feeding behavior of $\boldsymbol{D}$. maidis on the artificial diet. (A) Schematic representation of the green food coloring assay. (B) Colored diet located at the top end of the feeding chamber. (C) Green honeydew droplets on the wall of the feeding chamber. (D, E) Green-colored mouthparts and abdomen, respectively. Scale bar: $1 \mathrm{~mm}$. The black arrowheads in (B) and (C) point to D. maidis adults. (F) Upper graph: EPG waveform of $D$. maidis having access to the artificial. Double-headed arrows indicate longest time periods of active feeding. Lower graph: $8 \mathrm{~s}$ of active feeding corresponding to the yellow highlighted region of the upper graph. $\mathrm{X}$ axis: time (s), $\mathrm{Y}$ axis: voltage. 


\section{Figure 2}

(A)

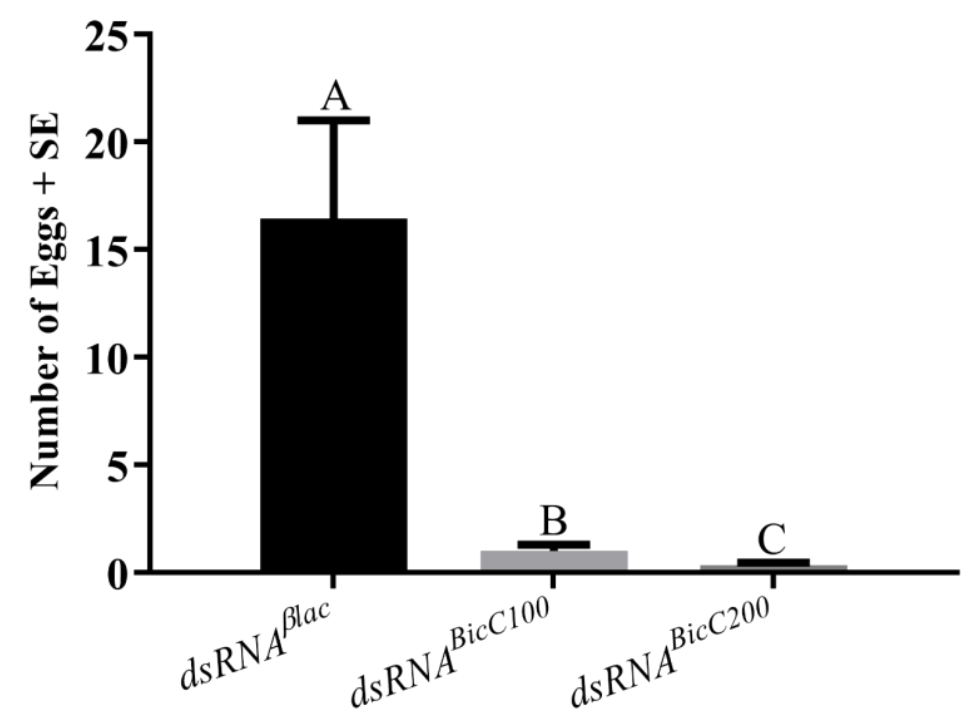

(B)

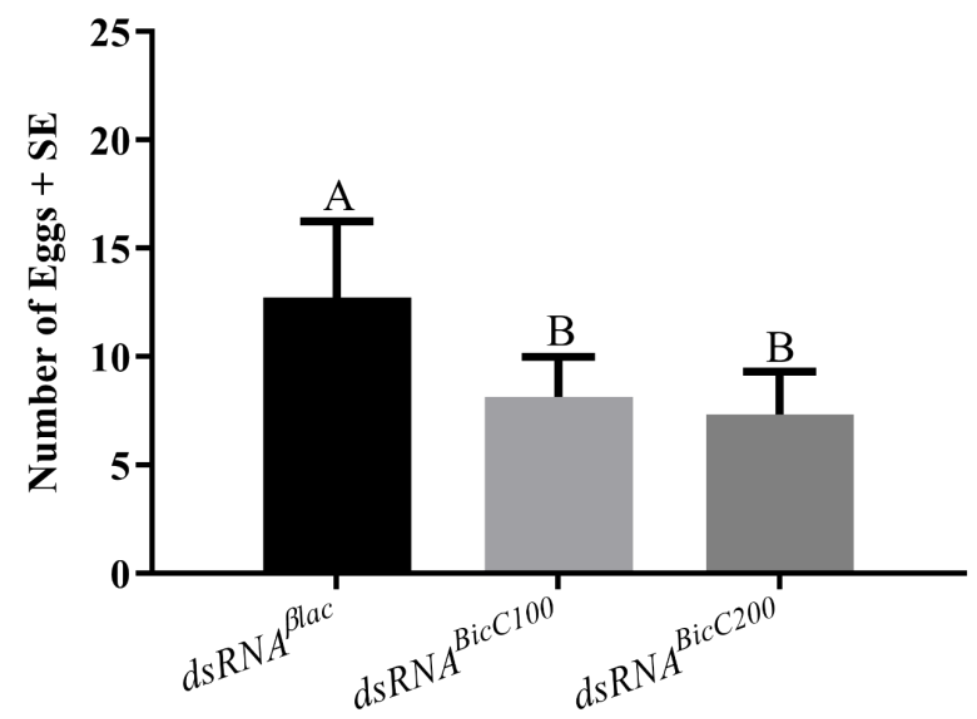

(C)

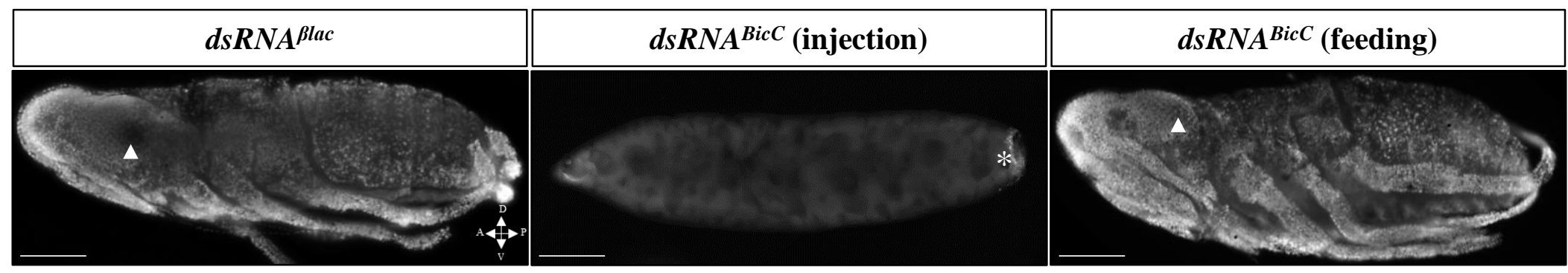

Ovipositions of $\boldsymbol{D}$. maidis females after dsRNA delivery. Ovipositions in the injection- (A) and feeding (B)-based experiments. The number of eggs laid by the females showed a significant effect of the treatment factor (microinjection: $\mathrm{p} \leq 0.0001$ and feeding: $\mathrm{p}=0.0026$ ). Each bar represents the mean number of eggs laid by $D$. maidis females and the standard error of the mean (SE). Values with the same letter are not significantly different according to contrasts in the mixed model

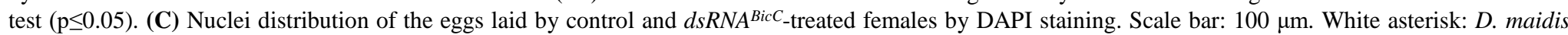
endosymbiont. White arrowhead: embryos' eye. A: anterior; P: posterior; D: dorsal; V: ventral. 
Figure 3

(A)

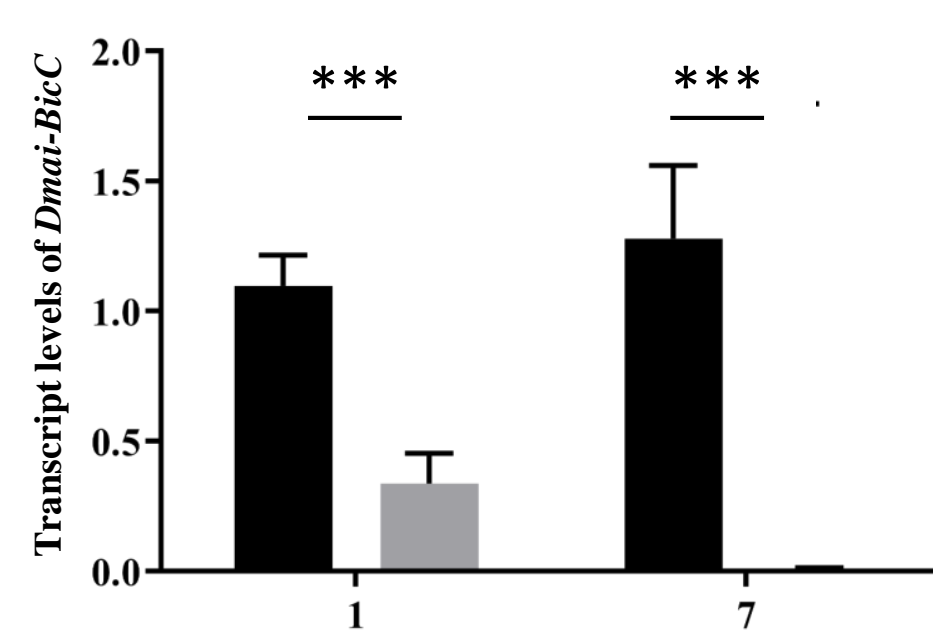

Time (days post treatment)
(B)

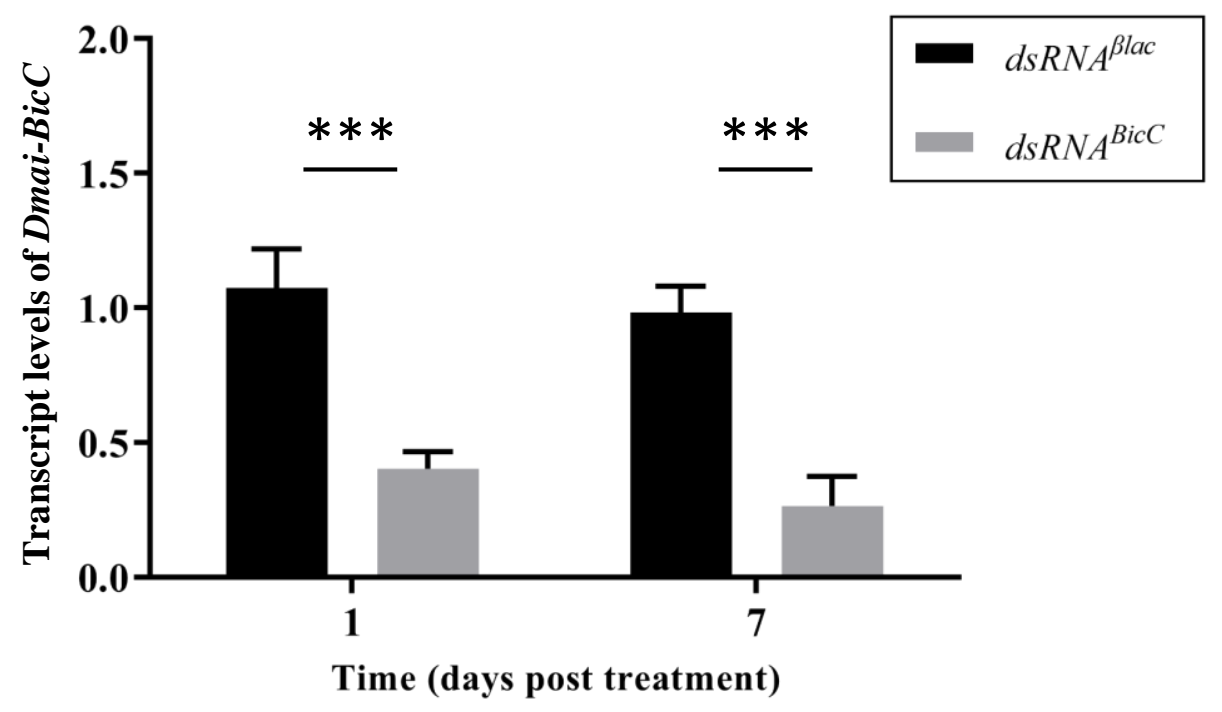

Expression levels of Dmai-BicC after dsRNA delivery. Transcript levels of Dmai-BicC during the progression of injection (A) or feeding (B)-based experiments. Expression was measured at 1 and 7 days after administration of $d s R N A^{B i c C}$ (gray bars) or $d s R N A^{\text {Blac }}$ (black bars) used as an experimental control. All values were referred to as the Dmai-BicC expression at 1-day post-treatment in females treated with $d s R N A^{\beta l a c}$. Each bar represents the mean and standard deviation (SD) of three biological replicates. $* * * \mathrm{p} \leq 0.005$ (ANOVA, LSD Fisher test). 


\section{Figure 4}

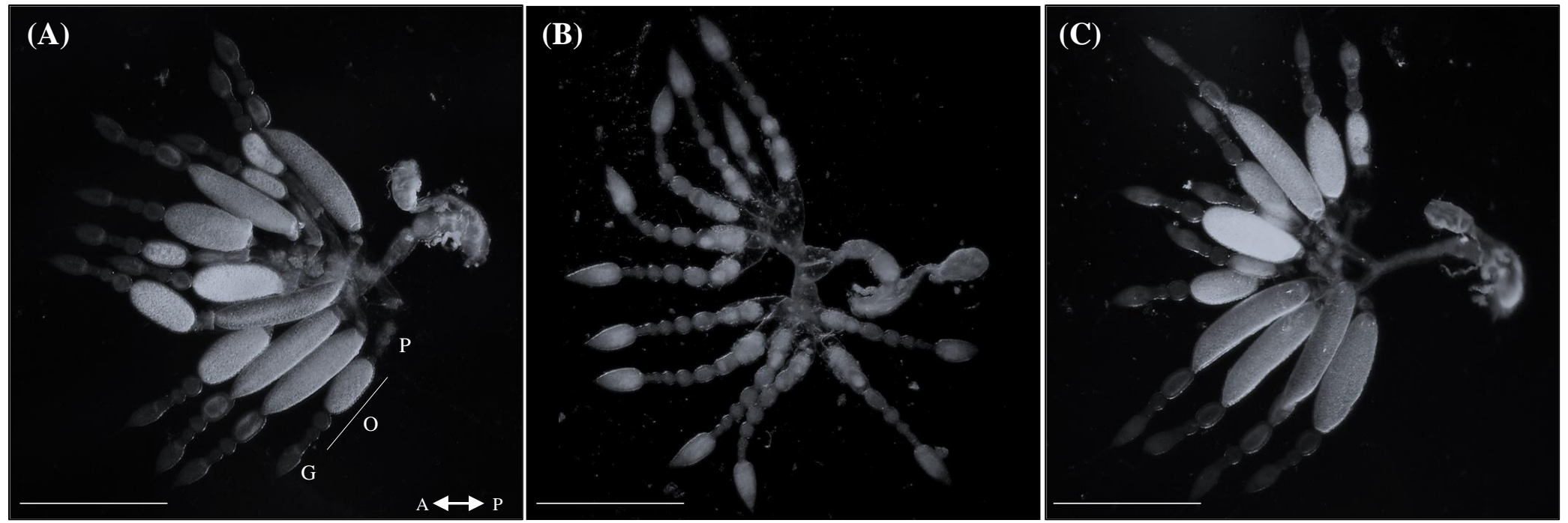

Effect of dsRNA on D. maidis female reproductive organs. Ovary morphology of a control (A) $d s R N A^{B i c}$-injected (B) and $d s R N A^{B i c}$-fed (C) female under dissecting microscope. Scale bar: $500 \mu \mathrm{m}$. G: germarium; O: oocytes and P: pedicle. A: anterior; P: posterior. 


\section{Figure 5}

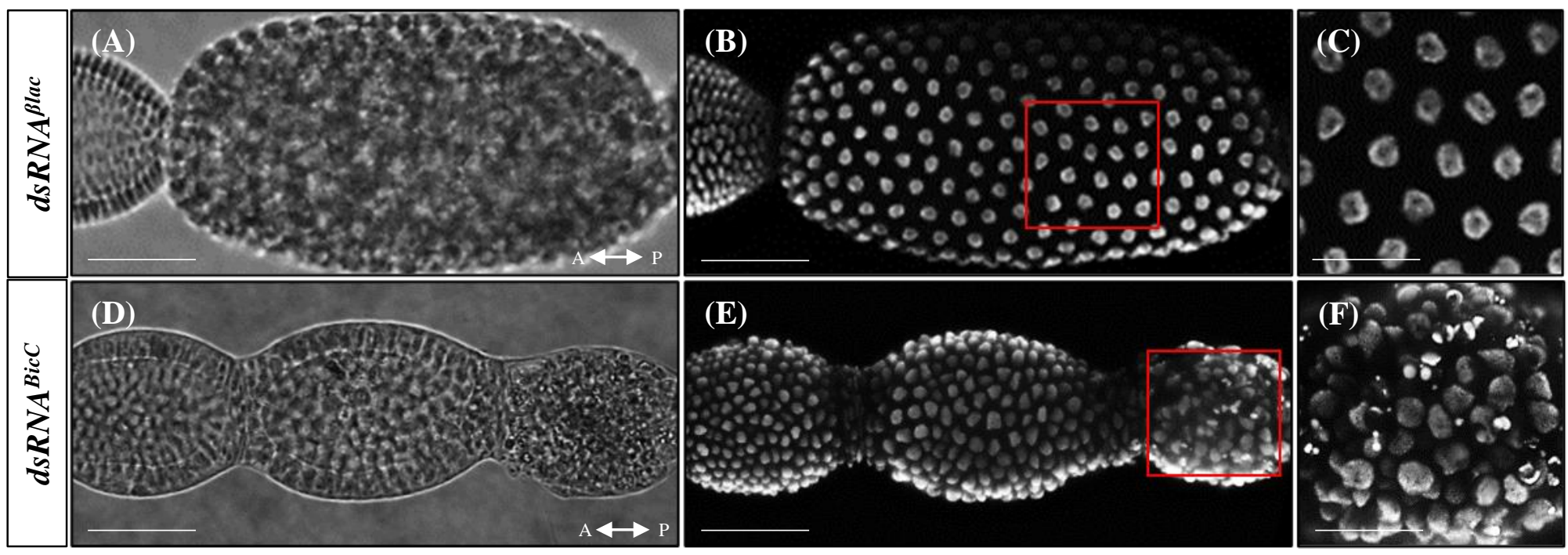

Effect of dsRNA on D. maidis follicular epithelium. Oocytes of control and $d s R N A^{B i c}$-injected females by differential interference contrast (DIC) microscopy (A, D) and their nuclei distribution by DAPI staining (B, E). Scale bar: $100 \mu \mathrm{m}$. (C, F) Follicular epithelium of control and $d s R N A^{B i c C}$-injected females showing the nuclei distribution of the highlighted regions in (B) and (E). Scale bar: $50 \mu \mathrm{m}$. 